\title{
Subject Index Vol. 4, No. 3, 1995
}

\section{Subject Index Vol. 4, No. 3, 1995}

Adenosine 168

Airway resistance, nasal 179

Angiotensin II 124,133

Aorta, rat 160

Arterial pressure 114,133

Atherosclerosis 150

Autonomic neurons 109,124,

133,142 Blood volume regulation 142

- - shift 186 Calcium channels 160

- intracellular, free 174 Cardiac output imbalance 186 Cardiovascular control 142

- neurons 124,133 Carotid body 109 Catecholamines 124 Central neurons $117,124,133$,

142 Chemoreceptor 109 Choline acetyltransferase 124 Coronary arteries 150 Cyclic GMP 109 Digoxigenin labelling 150 Discharge units, single and double

133 Efferent inhibition 109 Endothelium-derived relaxant factor 150 Foot shock 124 c-fos 117

Hypertension 117,124,133 Hypotension 117 Hypothalamus 117,124,142 Hypoxia 168 Immediate-early gene 117 Inositol-1,4,5trisphosphate 174

Intracranial hypertension 186 Left ventricular failure 186 Magnesium 160 Myocyte, ventricular 174 Nasal congestion 179 Nerves, sympathetic and parasympathetic 179 Nitric oxide 109,150 Opioid 124 - receptor 174

Oxygen supply-to-demand ratio 168

Paraventricular nucleus of hypothalamus 142

pH 168

Pulmonary edema 186

- hypertension 186

- volume loading 186 Receptor modulation 109 Rhinitis 179

Rostral ventrolateral medulla 124 ,

133 RU 38486124 Saponins 160 Sensory neurons 109 Signal transduction, cardiac

k-receptor 174 Skeletal muscle 168 Spironolactone 124 Spontaneously hypertensive rat

133 Sympathetic effects 186 